\title{
Self perceived satisfaction with dental appearance and desired treatment to improve aesthetics
}

\section{Enabulele J.E., Omo J.O}

Department of Restorative Dentistry, University of Benin, Benin City, Nigeria

\begin{abstract}
Objective: To assess the satisfaction with dental appearance, desired treatments to improve dental appearance, and factors that affect satisfaction with dental appearance among a group of Nigerian dental patients.
\end{abstract}

Methods: The data collection instrument was a modified questionnaire used in a previous study by Tin-Oo et al. It consisted of 3 sections: section 1 elicited information on the socio-demographic characteristics of the participants, section 2 determined level of satisfaction with the general appearance of their teeth and tooth colour, section 3 sought information on desire to undergo treatments to improve the appearance of their teeth as well as the desired treatment.

Data collected was analysed using the IBM Statistical Package for Social Science (SPSS) version 21.0.

Results: Less than half (45.1\%) of the respondents were dissatisfied with the general appearance of their teeth. More than half (53.3\%) of the respondents were dissatisfied with the colour of their teeth. A few $(10.7 \%)$ of the respondents felt their teeth were crowded while $24.6 \%$ felt their teeth were poorly aligned. Majority $(82.8 \%)$ wished to undergo treatment to improve the appearance of their teeth. A few $(12.9 \%)$ of the respondents who desired treatment to improve the appearance of their teeth desired orthodontic treatment for realignment, while $15.8 \%$ desired treatment to replace missing teeth. More than half $(67.3 \%)$ desired tooth whitening procedures to improve the appearance of their teeth.

Conclusion: Tooth shade plays a vital role in self-perceived satisfaction with dental appearance. Tooth whitening was the most desired treatment to improve dental appearance.

Keywords: satisfaction, dental appearance, tooth colour, perceived.

\section{INTRODUCTION}

Oral health is not only the absence of oral disease and dysfunction but also includes its influence on a person's social life and dento-facial self-confidence with dental appearance being an integral component of facial beauty. ${ }^{1}$ Dental aesthetics is aimed at creating beauty and attraction which ultimately elevates selfesteem of patients and also make patients satisfied with important and socially valued parts of their body. It is believed that minor discrepancies in dental aesthetics could have a significant effect on perceived oral health related quality of life $\mathrm{e}^{3.5}$ as well as have an impact on social appearance concern. ${ }^{3}$ Self-perception of dental aesthetics therefore, cannot be under estimated because in rendering aesthetic treatment the

\section{Correspondence: Omo J.O}

Department of Restorative Dentistry,

University of Benin,

Benin City, Nigeria

Tel: +234 8066164845

E-mail: julie.omo@uniben.edu

Received: 11/03/2017

Accepted 05/07/2017 patient receiving the treatment needs to be satisfied with the treatment. ${ }^{6,7}$

Treatments which improve dental aesthetics have been found to improve quality of life and psychological status. ${ }^{8}$ Patients who have interest in improving their dental appearance have been found to frequently demand for tooth whitening treatments, anterior teeth restoration and orthodontic treatment.'

There may be possible differences in aesthetic perception between clinician and patient which could create problems during treatment if not properly recognized..$^{10}$ Clinicians must therefore be mindful of their patient's desire to achieve favorable results ${ }^{11}$ as the overriding importance of psychological implications of dental aesthetics over physiological changes have been demonstrated. ${ }^{12}$ Dental professionals have to be aware of the psychological triggers of treatment demands of the patients, the effect of dental appearance in patients' satisfaction, and subsequently the impact of this satisfaction in treatment success. ${ }^{13}$

A United Kingdom report revealed that $28 \%$ of adults were dissatisfied with the appearance of their teeth. ${ }^{11}$ Therefore understanding the prevalence of 
dissatisfaction with the present aesthetics of a population and their desired treatments to improve aesthetics can assist in the development of strategies for intervention designed to improve aesthetics. ${ }^{14}$

The aim of this study was to assess the satisfaction with dental appearance, desired treatments to improve dental appearance, and factors that affect satisfaction with dental appearance among a group of Nigerian dental patients.

\section{METHODS}

This study was a descriptive cross-sectional study involving 125 consenting adult patients who sort dental care for the first time at the Oral diagnosis clinic of the Dental Centre of the University of Benin Teaching Hospital over a four-month period (August to November 2016). Informed consent was obtained from all the participants before commencement of the study. The data collection instrument was a modified questionnaire used in a previous study by Tin-Oo et al. ${ }^{15}$ It consisted of 3 sections: section 1 elicited information on the socio-demographic characteristics of the participants (gender, age, marital status, occupation and highest level of education attained). Section 2 consisted of Lickert-type scale response anchors (very dissatisfied, dissatisfied, unsure, satisfied and very satisfied) to determine level of satisfaction with the general appearance of their teeth and tooth colour as well as self-perceived satisfaction with dental appearance. Section 3 sought information on desire to undergo treatments to improve the appearance of their teeth as well as the desired treatment.

Data collected was analysed using the IBM Statistical Package for Social Science (SPSS) version 21.0. The collated data was subjected to descriptive analysis in the form of frequencies, percentages, cross tabulations, mean and standard deviation.Chi square was used to determine association between variables with $p$ set at $=$ 0.05 .

\section{RESULTS}

A total of 125 questionnaires were administered, 122 were returned giving a response rate of $97.6 \%$. The respondents' age ranged from 14 to 80 years with a mean age of $33.11 \pm 14.3$ with those aged $25-40$ years accounting for $43.5 \%$. There was a slight female preponderance with a male female ratio of $1: 1.1$. Majority $(77.9 \%)$ of the respondents had attained tertiary education with $48.4 \%$ being dependents and
$59 \%$ single (Table 1$)$.

Less than half $(45.1 \%)$ of the respondents were dissatisfied with the general appearance of their teeth. More than half $(53.3 \%)$ of the respondents were dissatisfied with the colour of their teeth. There was statistically significant association between satisfaction with general appearance of the teeth and satisfaction with tooth colour $(\mathrm{p}<0.0001)$. A higher proportion $(69.1 \%)$ of those dissatisfied with their general dental appearance were also dissatisfied with their tooth colour, while more than half (56.9\%) of those satisfied with the general appearance of their teeth were satisfied with the colour of their teeth.

However there was no statistically significant association between satisfaction with general appearance of teeth and sociodemographic characteristics of the respondents (Table 2).

More of the respondents who were dependents were dissatisfied with the colour of their teeth and this was statistically significant ( $p=0.007)$. Single respondents tended to be more dissatisfied with the colour of their teeth and this was statistically significant $(\mathrm{p}=0.002)$.

Table 3 showed a statistically significant association between age group of the respondents and satisfaction with tooth colour with satisfaction increasing with age $(p=0.001)$.

A few $(10.7 \%)$ of the respondents felt their teeth were crowded while $24.6 \%$ felt their teeth were poorly aligned. Self-assessed report of protruding teeth was reported by $10.7 \%$ of the respondents. Less than a fifth $(19.7 \%)$ of the respondents were of the opinion they had dental caries in their anterior teeth. A few (7.4\%) claimed to have non aesthetic fillings in their anterior teeth. Less than a quarter $(21.3 \%)$ of the respondents reported they had fractured teeth.

Majority $(82.8 \%)$ wished to undergo treatment to improve the appearance of their teeth. There was a statistically significant association between gender and desire to undergo treatment to improve teeth appearance with a higher proportion of females expressing such desires ( $\mathrm{p}=0.003$ ) (Table 4 ).

A few $(12.9 \%)$ of the respondents who desired treatment to improve the appearance of their teeth desired orthodontic treatment for realignment, while $15.8 \%$ desired treatment to replace missing teeth. More than half $(67.3 \%)$ desired tooth whitening procedures to improve the appearance of their teeth. Only 5.0\% desired to create midline diastema while $5.9 \%$ and $14.9 \%$ desired to cover up their teeth with crowns and to have tooth coloured fillings 
respectively.

There was increased desire for tooth whitening procedures with decreasing age and this was statistically significant $(\mathrm{p}=0.01)$. In like manner, there was increased desire to replace missing teeth among respondents aged 41 to 65 years and this was statistically significant $(p=0.001)$. There was statistically significant association between marital

status and desire to have tooth whitening procedures with a higher proportion of single respondents desiring it.

\section{Table 1: Sociodemographic distribution}

\begin{tabular}{|c|c|c|}
\hline Characteristics & Frequency(n) & Percent (\%) \\
\hline \multicolumn{3}{|l|}{ Gender } \\
\hline Male & 59 & 48.4 \\
\hline Female & 63 & 51.6 \\
\hline \multicolumn{3}{|l|}{ Level of Education } \\
\hline Primary & 7 & 5.7 \\
\hline Secondary & 20 & 16.4 \\
\hline Tertiary & 95 & 77.9 \\
\hline \multicolumn{3}{|l|}{ Marital Status } \\
\hline Single & 72 & 59 \\
\hline Married & 50 & 41 \\
\hline \multicolumn{3}{|l|}{ Occupation } \\
\hline Professional/skilled & 49 & 40.2 \\
\hline Semiskilled/unskilled & 14 & 11.5 \\
\hline Dependents & 59 & 48.4 \\
\hline \multicolumn{3}{|l|}{ Age groups } \\
\hline$<25$ years & 49 & 40.2 \\
\hline 25 - 40 years & 53 & 43.4 \\
\hline 41 - 65 years & 20 & 16.4 \\
\hline Total & 122 & 100.0 \\
\hline
\end{tabular}


Table 2: Association between sociodemographic characteristics and satisfaction with general appearance

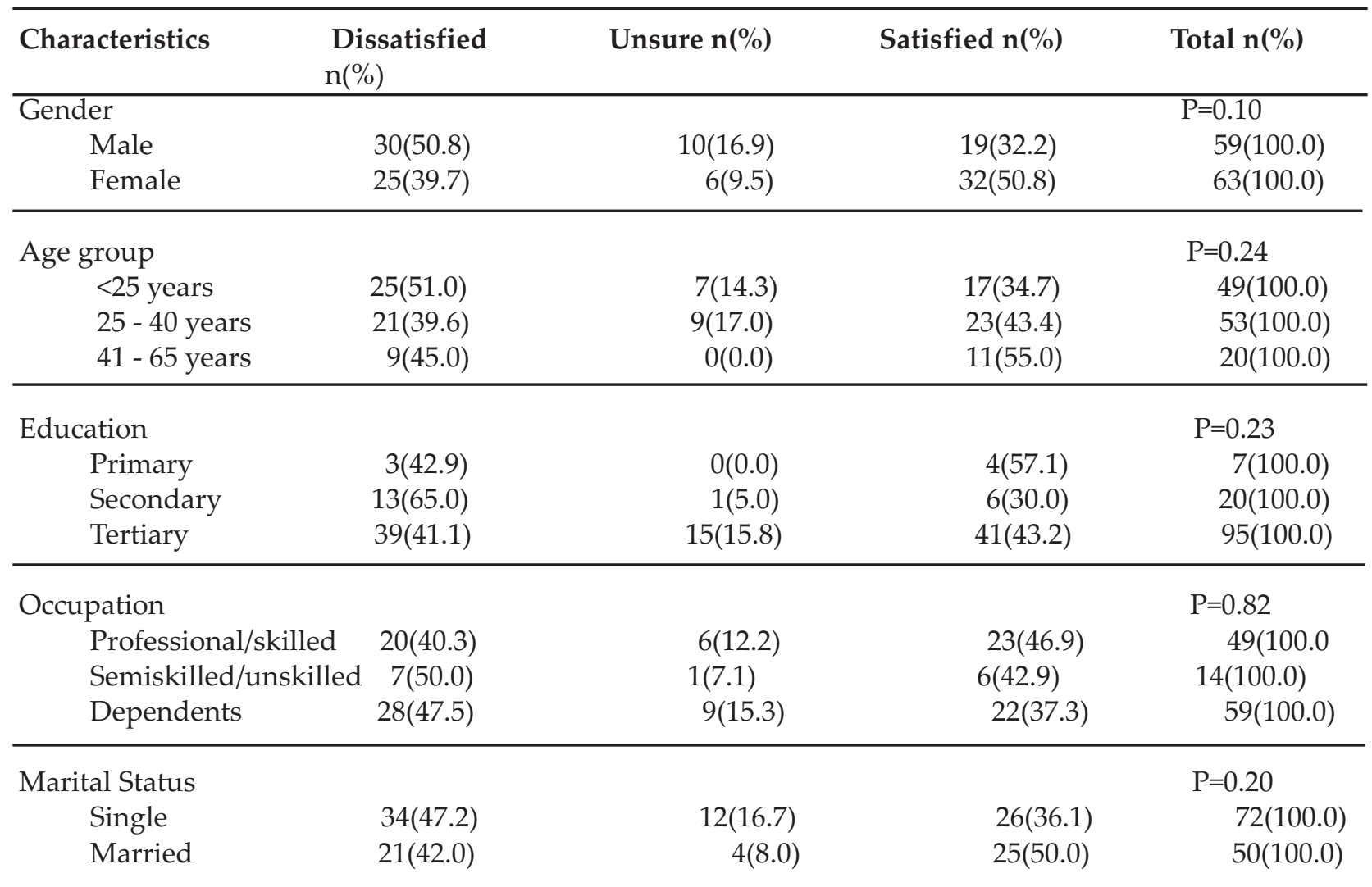

Table 3: Association between sociodemographic and satisfaction with tooth colour.

\begin{tabular}{|c|c|c|c|c|}
\hline Characteristics & ssatisfied n(\%) & Unsure n(\%) & Satisfied n(\%) & Total n(\%) \\
\hline Gender & & & & $\mathrm{P}=0.10$ \\
\hline Male & $37(62.7)$ & $7(11.9)$ & $15(25.4)$ & $59(100.0)$ \\
\hline Female & $28(44.4)$ & $8(12.7)$ & $27(42.9)$ & $63(100.0)$ \\
\hline Age group & & & & $\mathrm{P}=0.001$ \\
\hline$<25$ years & $35(71.4)$ & $7(14.3)$ & $7(34.7)$ & $49(100.0)$ \\
\hline 25 - 40 years & $24(45.3)$ & $7(13.2)$ & $22(41.5)$ & $53(100.0)$ \\
\hline 41 - 65 years & $6(30.0)$ & $1(5.0)$ & $13(65.0)$ & $20(100.0)$ \\
\hline Education & & & & $\mathrm{P}=0.32$ \\
\hline Primary & $2(28.6)$ & $2(28.6)$ & $3(42.9)$ & 7(100.0) \\
\hline Secondary & $8(40.0)$ & $3(15.0)$ & $9(45.0)$ & $20(100.0)$ \\
\hline Tertiary & $55(57.9)$ & $10(10.5)$ & $30(31.6)$ & $95(100.0)$ \\
\hline Occupation & & & & $\mathrm{P}=0.007$ \\
\hline Professional/skilled & $25(51.0)$ & $4(8.2)$ & $20(40.8)$ & $49(100.0$ \\
\hline Semiskilled/unskilled & $2(14.3)$ & $3(21.4)$ & $9(64.3)$ & $14(100.0)$ \\
\hline Dependents & $38(64.4)$ & $8(13.6)$ & $13(22.0)$ & $59(100.0)$ \\
\hline Marital Status & & & & $\mathrm{P}=0.002$ \\
\hline Single & $47(65.3)$ & $9(12.5)$ & $16(22.2)$ & $26(52.0)$ \\
\hline Married & $18(36.0)$ & $6(12.0)$ & $26(52.0)$ & $52(100.0)$ \\
\hline
\end{tabular}


Table 4: Association between socio demographic characteristics and desire to undergo treatment to improve teeth appearance

\begin{tabular}{|c|c|c|c|}
\hline Characteristics & sire to und & tment & Total \\
\hline Yes & $\mathrm{n}(\%)$ & No $n(\%)$ & $\mathrm{n}(\%)$ \\
\hline Gender & & & $\mathrm{P}=0.003$ \\
\hline Male & $55(93.2)$ & $4(6.8)$ & $59(100.0)$ \\
\hline Female & $46(73.0)$ & $17(27.0)$ & $63(100.0)$ \\
\hline Age group & & & $\mathrm{P}=0.91$ \\
\hline$<25$ years & $41(83.7)$ & $8(16.3)$ & $49(100.0)$ \\
\hline 25 - 40 years & $43(81.1)$ & $10(13.2)$ & $53(100.0)$ \\
\hline 41 - 65 years & $17(85.0)$ & $3(15.0)$ & $20(100.0)$ \\
\hline Level of Education & & & $\mathrm{P}=0.70$ \\
\hline Primary & $2(71.4)$ & $2(28.6)$ & $7(100.0)$ \\
\hline Secondary & $17(85.0)$ & $3(15.0)$ & $20(100.0)$ \\
\hline Tertiary & $79(83.2)$ & $16(16.8)$ & $95(100.0)$ \\
\hline Occupation & & & $\mathrm{P}=0.76$ \\
\hline Professional/skilled & $42(85.7)$ & $7(14.3)$ & $49(100.0$ \\
\hline Semiskilled/unskilled & 11(78.6) & $3(21.4)$ & $14(100.0)$ \\
\hline Dependents & $48(81.4)$ & $11(18.6)$ & $59(100.0)$ \\
\hline Marital Status & & & $\mathrm{P}=0.43$ \\
\hline Single & $58(80.6)$ & $14(19.4)$ & $72(100.0)$ \\
\hline Married & $43(86.0)$ & $7(14.0)$ & $50(100.0)$ \\
\hline Total & $101(82.8)$ & 21(17.2) & $122(100.0)$ \\
\hline
\end{tabular}

\section{DISCUSSION}

Various factors have been reported to affect dental appearance and these include tooth colour, shape, position, quality of restoration, general arrangement of the dentition especially the anterior teeth, ${ }^{2,4,5,9,11,15-18}$ presence of fractured anterior teeth, ${ }^{5}$ shape of the dental $\operatorname{arch}^{4}$ as well as individual and cultural factors. ${ }^{19}$ Prevalence of self-perceived dissatisfaction with general dental appearance observed in this study was similar to that of a previous study in Serbia, ${ }^{20}$ higher than US study ${ }^{11}$ and a previous Nigerian study. ${ }^{21}$ This difference may be due to variations in self-perception and subjective evaluation of dental appearance and aesthetics. ${ }^{20}$ Prevalence of dissatisfaction with tooth shade was similar to reports obtained from Turkey ${ }^{4}$ and China. ${ }^{22}$

Tooth colour is a critical factor that influences satisfaction with smile appearance ${ }^{11}$ and is also a major factor with regard to dental aesthetics. ${ }^{9}$ It is the most common smile component causing dissatisfaction among subjects. ${ }^{1}$ This was observed in this study as more than half of the respondents who were dissatisfied with their general dental appearance were also dissatisfied with the colour of their teeth.

Socio-demographic factors such as gender, age and educational level have been shown to have an impact on an individual's perception of dental aesthetics. ${ }^{19}$ It was observed that majority of the respondents who were dissatisfied with the colour of their teeth were dependents and single respondents who were mainly students in tertiary institutions. This becomes important as the younger age groups tend to pay more attention to their appearance ${ }^{23}$ unlike the older age group who are indifferent about their dental appearance.

Poor tooth alignment and crowding were among the most common malocclusion traits reported in the literature. ${ }^{24,25}$ However, the findings of this study is similar to a previous study by Algamdi ${ }^{13}$ and showed that only a few of the respondents felt their teeth were crowded and others felt their teeth were poorly aligned and therefore needed orthodontic treatment. 
This may be a reflection of the low level of awareness of malocclusion on patient perceived satisfaction of facial appearance. ${ }^{13}$

Only a few respondents claimed to have dental caries or non-aesthetic filling on the anterior teeth. The anterior teeth play a crucial role in dental appearance especially when a person smiles or speaks, part of the anterior teeth is displayed and this becomes unsightly when the teeth are carious or have a non-aesthetic anterior filling with possible great impact on satisfaction with appearance.

Women tend to be more concerned about their appearance than men because their appearance is central to how they are evaluated by others and their physical appearance is more important for their dating success than is true of men. ${ }^{26}$ Females have been found to be more critical when judging their dental appearance ${ }^{27,28}$ hence, they may desire treatment to improve their appearance, but in this study it was observed that more males desired treatments to improve their appearance.

Tooth whitening was the most prevalent treatment desired to improve dental appearance with the younger age group being predominant a finding similar to that by Algamdi. ${ }^{13}$ This lends credence to the fact that satisfaction with tooth colour strongly impacts on satisfaction with dental appearance. ${ }^{5}$

Missing teeth have been found to be predominant among the elderly, as periodontal diseases increase with age, hence the increased desire by this group of respondents to replace missing teeth. Replacement of missing teeth tends to improve dental aesthetics as well as facial appearance.

\section{LIMITATION OF THE STUDY}

This study was carried out among patients who presented for treatment at the oral diagnosis unit and not among the general public.

It was also conducted in the south-south geopolitical region of the country and may not be representative of the entire geopolitical regions.

\section{CONCLUSION}

Tooth shade plays a vital role in self-perceived satisfaction with dental appearance. Tooth whitening was the most desired treatment to improve dental appearance. This was found to be prevalent among the younger age group.

Recommendation: Further studies should be carried out among non-patients and other geopolitical regions to validate and expand the body of knowledge.

\section{REFERENCES}

1) Afroz S, Rathi S, Rajput G, Rahman SA. Dental esthetics and its impact on psycho-social wellbeing and dental self-confidence: a campus based survey of North Indian University. J Indian Prosthodont Soc 2013;13:455-460.

2) Silva GC, Castilhos ED, Masotti AS, RodriguesJr SA. Dental aesthetic self-perception of Brazilian dental students. RSBO 2012;9:375-381.

3) Klages U, Bruckner A, Zentner A. Dental aesthetics, self-awareness and oral healthrelated quality of life in young adults. Eur J Orthod 2004;26:507-514

4) Akarslan ZZ, Sadik B, Erten H, Karabulut E. Dental esthetic satisfaction, received and desired dental treatments for improvement of aesthetics. Indian J Dent Res 2009;20:195-200.

5) Al-Zarea BK. Satisfaction with appearance and the desired treatment to improve aesthetics. Int J Dent 2013;doi/10.1155/2013/912368.

6) Grzywacz I. The value of the aesthetic component of the index of orthodontic treatment need in the assessment of subjective orthodontic treatment need. Eur J Orthod 2003;25:57-63.

7) Yeh M, Koochek A, Vlaskalic V, Boyd R, Richmond $S$. The relationship of two professional occlusal indexes with patients' perceptions of aesthetic, function, speech and orthodontic treatment need. Am J Orthod Dentofacial Orthop 2000;118:421-428.

8) Gross Mann AC, Hassel AJ, Schilling O, Lehmann F, Kobo A, Rammelsberg P. Treatment with double crown-retained removable partial dentures and oral health-related quality of life in middle and high-aged patients. Int J Prosthodont 2007; 20:576-578.

9) Samorodnitzky-Naveh GR, Geiger SB, Levin L. Patients' satisfaction with dental aesthetics. J Am Dent Assoc 2007;138:805-808.

10) Ward DH. A study of dentists' preferred maxillary tooth width proportions: comparing the recurring aesthetic dental proportion to other mathematical and naturally occurring proportions. J Esthet Restor Dent 2007;19:324337.

11) Qualtrough AJ, Burke FJ. A look at dental 
aesthetics. Quintessence Int 1994;25:7-14. Brisman AS, Hirsch SM, Paige HH, Hamburg M, Gelb M. Tooth shade preferences in older adults. Gerodontia 1985;1:130-133.

12) Brisman AS, Hirsch SM, Paige HH, Hamburg M, Gelb M. Tooth shade preferences in older adults. Gerodontia 1985;1:130-133.

13) Alghamdi ASA. Satisfaction with dental appearance and desired esthetic treatment in Saudi dental patients. EJPMR. 2016, 3:126-130

14) Grzic R, Spalj S, Lajnert V, Glavicic S, Uhac I, Pavicic DK. Factors influencing a patient's decision to choose the type of treatment to improve dental esthetics. Vojnosanit Preql 2012;69:978-985.

15) Tin-Oo MM, Saddki N, Hassan N. Factors influencing patient satisfaction with dental appearance and treatments they desire to improve aesthetics. BMC Oral Health 2011; Doi; 10.1186/1472-6831-11-6.

16) Joiner A, Hopkinson I, Deng Y, Westland S. A review of tooth colour and whiteness. J Dent 2008;36:S2-S7.

17) Kershaw S, Newton JT, Williams DM. The influence of tooth colour on the perception of personal characteristics among female dental patients: comparison of unmodified, decayed and "whitened" teeth. Br Dent J 2008;204;E9

18) Al-Omiri MK, Karasneh JA, Lynch E, Lamey PJ, Clifford TJ. Impacts of missing upper anterior teeth on daily living. Int Dent J 2009;59:127-132.

19) Odioso LL, Gibb RD, Gerlach RW. Impact of demographic, behavioral, and dental care utilization parameters on tooth color and personal satisfaction. Compend Contin Educ Dent 2000;29:S35-S41.

20) Strajnic L, Bulatovic D, Stancic I, Zivkovic R. Self-perception and satisfaction with dental appearance and aesthetics with respect to patients' age, gender, and level of education.
Srp Arh Celok Lek. 2016;144:580-589

21) Azodo CC, Ogbomo AC. Self-evaluated dental appearance satisfaction among young adults. Ann Med Health Sci. 2014; 4:603-607

22) Xiao J, Zhanon $X$, Zhu W, Zhang B, Li J, Xu X. The prevalence of tooth discolouration and the self-satisfaction with tooth colour in Chinese urban population. J Oral Rehabil. 2007; 34:351-60.

23) Vallittu P, Vallittu A, Lassila V: Dental aesthetics--a survey of attitudes in different groups of patients. Journal of Dentistry. 1996, 24 (5): 335-338.

24) Jonsson T, Arnlaugsson S, Karlsson K, Ragnarsson B, Arnarson E, Magnusson T: Orthodontic treatment experience and prevalence of malocclusion traits in an Icelandic adult population. American Journal of Orthodontics and Dentofacial Orthopedics. 2007, 131 (1): 8.e11-18.e18.

25) Borzabadi-Farahani A, Borzabadi-Farahani A, Eslamipour F: Malocclusion and occlusal traits in an urban Iranian population. An epidemiological study of 11- to 14-year-old children. European Journal of Orthodontics. 2009, 31 (5): 477-484.

26) Jackson LA. Physical appearance and gender. Albany NY: Suny press 1992.

27) Hassel AJ, Wegener I, Rolko C, Nitschke I. Selfrating of satisfaction with dental appearance in an elderly German population. Int Dent J 2008 Apr;58(2):98-102.

28) Maghaireh GA, AIzraikat H, Taha NA. Satisfaction with Dental Appearance and Attitude toward improving Dental Esthetics among Patients attending a Dental Teaching Center. J Contemp Dent Pract 2016;17(1):16-21. 